\title{
EL DERECHO Y LA BIOÉTICA: ESTADO ACTUAL DE LAS CUESTIONES EN BRASIL
}

\author{
Eduardo de Oliveira Leite*
}

Resumen: En la presente monografía, el autor examina las relaciones existentes entre los ámbitos jurídico y bioético, haciendo especial referencia al estado actual de la problématica en Brasil. A este respecto, señala que el Derecho, como norma imperativa, ha encontrado gran dificultad en la reglamentación de las materias bioéticas, pues concurre con otros sistemas normativos, no emanados de los poderes públicos, sino que de la comunidad científica. Con todo, su reconocimiento por parte del ordenamiento jurídico las legitima, al reflejar los valores dominantes en la sociedad, permitiendo su inserción en el medio social.

Palabras clave: Bioética, derecho, dignidad humana, reproducción asistida, embrión

\section{LAW AND BIOETHICS: PRESENT STATUS IN BRASIL}

\begin{abstract}
In this monograph, the author examines the existing relationship between the juridical and ethical scopes, emphasizing especially the present status of the subject in Brasil. Accordingly, he points out that Law, as an imperative norm, has found great difficulty in establishing rules for bioethical matters, because it rules simultaneously with other normative systems that are not issued by the public authorities, but by the scientific community. Nevertheless, its juridical's recognition legitimates them because it reflects the predominant values in society, allowing them to be inserted in the social system.
\end{abstract}

Key Words: Bioethics, law, human dignity, assisted reproduction, embryo

\section{O DIREITO E A BIOÉTICA: ESTADO ATUAL DAS QUESTÕES NO BRASIL}

Resumo: Na presente monografia, o autor examina as relações existentes entre os campos jurídico e bioético, fazendo especial referência ao estado atual da problemática no Brasil. A este respeito, assinala que o Direito, como norma imperativa, tem encontrado grande dificuldade no ordenamento das matérias bioéticas, pois as mesmas provem de outros sistemas normativos que não os emanados dos poderes públicos, mas sim, da comunidade científica. Entretanto, o reconhecimento por parte do ordenamento jurídico as legitima ao refletir os valores dominantes na sociedade, permitindo, assim, sua inserção no meio social

Palavras chave: Bioética, direito, dignidade humana, reprodução assistida, embrião

* Doctor en Derecho Privado. Post - Doctor en Derecho de Familia. Profesor Titular de Derecho Civil. Miembro del Consejo Ejecutivo de la International Society of Family Law y Abogado en Paraná - Brasil.

Correspondencia: eoleite@netbank.com.br 


\section{Introducción}

Fue con inmensa alegría que recibí la invitación formulada por el profesor Adelio Misseroni, Consultor Externo del Programa Regional de Bioética, para participar en la publicación de la Revista del Programa Regional de Bioética de la Organización Panamericana de la Salud - Organización Mundial de la Salud.

Es fundamental que en América del Sur existan canales de divulgación y promoción del saber y del conocimiento sudamericanos, especialmente en una materia de trascendental importancia como la Bioética, que ha generado, en todo el mundo, una reacción que va desde la más amplia e irrestricta aceptación hasta la más inflexible crítica. Pero, mientras en Europa, en notables y memorables conferencias, los países han estado discutiendo desde hace algunos años los más diversos aspectos relativos al infinito tema, en América del Sur, por razones todavía no suficientemente determinadas, lo que se constata es un "aislamiento" regional e ideológico que, en lugar de unir países hermanos y provenientes de una misma raíz, genera profundos fosos de aislamiento, individualismo y esclerosis intelectual, inadmisibles en época de constante globalización.

La propuesta, pues, de discutir en una Revista la tendencia de los diversos países componentes del cono sur es, a todas luces, oportuna y sólo puede ser aceptada con absoluto entusiasmo, aplausos e irrestricto apoyo. Que esta publicación sirva como semilla inicial que, germinando, creará, a lo mejor, una Asociación Latinoamericana de Bioética -ALAB- que funcionaría como un foro permanente de nuestras tendencias, de nuestras dudas y problemas, de nuestros planes y perspectivas para el futuro.
Ciertamente, la publicación de la Revista Acta Bioethica ya produce sus frutos benéficos y el lanzamiento de un número dedicado a Derecho y Bioética, redundará en una valiosa forma de estrechar más y mejor los lazos todavía tenues de naciones vecinas y hermanas.

En Brasil, como bien ha evaluado Renato Sérgio Balão Cordeiro, "somos consumidores de innovaciones biotecnológicas, equipamientos y productos y percibimos un desfase enorme de la reflexión ética sobre estos procesos y productos"(1). Ahora bien, el desarrollo de una Bioética exige de nosotros, profesionales y estudiosos, investigadores y alumnos, la discusión histórica del poder de la ciencia en una economía de mercado, de manera tal de poder rescatar la construcción de la dignidad humana. $\mathrm{O}$ sea, la sociedad puede $\mathrm{y}$ debe ser compañera crítica en todas estas cuestiones.

Y el espacio de discusión abierto por una Revista dedicada al tema específico rescata, de forma incuestionable, la dimensión política (en el sentido de la determinación de las conductas y reapropiación de temas que dicen relación con la acción colectiva) y la dimensión cultural y humanista (de escuchar la opinión de los científicos y de los legos) del tema, hasta entonces, reducido a la apreciación "elitista" de segmentos altamente especializados (léase, científicos, juristas, filósofos, entre otras categorías citables).

Sólo por eso, por la posibilidad de pensar, evaluar y reflexionar que proporciona a todos, ofreciendo "a nosotros mismos un tiempo para la reflexión, un tiempo para compartir luchando desesperadamente contra el frenesí de los tiempos modernos que nos obliga a correr"'( 1 , p.15), la propuesta de la OPS/OMS es altamente válida, porque sirve de premisa desencadenadora de nuevas proposiciones, revistiéndose de fundamental importancia. 
"En la pasión por el conocimiento debemos saber lo que estamos haciendo, dar sentido a nuestras relaciones y evitar hechos indeseables consumados. Los desacuerdos deben ser pensados y encarados con profundidad"(1).

\section{EI suceso "Dolly" y la repercusión en la aldea global}

Cuando hablamos de inseminación artificial, fecundación in vitro, madres sustitutas, ingeniería genética y lucha contra malformaciones congénitas; cuando nos referimos a la extracción y sustitución de órganos, clonación, experimentos sobre personas, control del dolor, prolongación de la vida, eutanasia y medidas paliativas; cuando nos referimos a estas realidades, nos estamos refiriendo a la Bioética.

Es decir, estamos refiriéndonos a la disciplina que "examina y discute los aspectos éticos relacionados con el desarrollo y las aplicaciones de la biología y medicina, indicando los caminos y maneras de respetarse el valor de la persona humana"(2).

Cuando se producen noticias explosivas o "escándalos", como sucedió recientemente con la clonación de la oveja Dolly, la Bioética es invocada, resurge vehemente y sigue presente.

Y las cuestiones por ella suscitadas dividen las opiniones y el tema se hace objeto de debates, cuando no de combates y, casi siempre -como bien ha apreciado Volnei Garrafa-, "objeto de batallas ideológicas que montan trincheras contra los defensores de posiciones contrarias", en nítida tendencia maniqueísta: unos encaran los avances de la ciencia como "obra del demonio" y, en el extremo opuesto, se constata su endiosamiento.
Las posiciones radicales y antagónicas “incurren en el riesgo de alimentar, en la esfera cultural, la intolerancia y, en la esfera práctica, el dogmatismo"(3), cuando el camino -como acertadamente ha indicado Garrafa- está en el equilibrio, "en la búsqueda de soluciones moralmente aceptables y prácticamente útiles".

La solución, sin duda, debe ser buscada en el término medio donde, casi siempre, reposan tranquilos el buen criterio y lo razonable.

Y estos debates, como era de esperarse, remiten -independientemente del sensacionalismo de los medios de comunicación- las prácticas biomédicas al terreno cotidiano, lo que antes era excepcional. La gran ventaja de la divulgación de las noticias y del alarde que, naturalmente, las cercan, se resume, a lo mejor, en la idea de que, lo que antes era velado y, de cierta forma, atributo de la minoría (de aquellos segmentos especializados y elitistas a los que nos hemos referido inicialmente) se hace público, conocido de todos, observable por diversos segmentos sociales.

En realidad, los sectores especializados -y estamos aquí pensando en los sectores dedicados al Derecho, a la Medicina o a la Éticase abren para toda la comunidad. Y esta apertura, altamente favorable, provoca una aireación de ideas, pensamientos y críticas, fundamental para la correcta apreciación de los temas en discusión.

El gran público pasa a tomar parte en el debate, o sea, pasa a ocupar una postura activa frente a la anterior absoluta pasividad.

Y esto ya es válido en la medida que tal actitud contribuye a la construcción solidaria y democrática, por la comunidad, de una "ética de la vida" o de aquello que Volnei Garrafa ha llamado "Estatuto de la Vida". 
Lo que caracteriza estas prácticas (y que justifica, en parte, la reacción inédita de los medios de comunicación) es que, habiéndose tornado más atrevidas, gracias a un desarrollo tecnológico inusitado, ellas envuelven, a partir de ahora, la vida humana de forma integral aprehendiéndola, dominándola y corrigiéndola, de acuerdo con los intereses en cuestión, es decir, buscando mejorar sus calidades y haciendo que sus fronteras retrocedan, como si fuéramos "aprendices de Dios"1.

En la medida que los destinos de la raza humana se encuentran en discusión (y la divulgación de las investigaciones científicas no siempre es hecha con la transparencia exigible en estas materias), el debate público gana un realce extraordinario porque, vía discusión, ejerce un "control" si no efectivo (como se podría pretender en un primer momento), educativo, sobre la eventual libertad de la industria en la manipulación de tecnologías y objetivos comerciales ${ }^{2}$.

Prueba de lo que se está afirmando es reconocible en el consentimiento libre e

\footnotetext{
La expresión es de la célebre civilista belga, Marie Thérese Meulders-Klein. Ver, en este sentido, su magistral articulo, titulado, Le droit de l' enfant face au droit à l' enfant et les procréations médicalement assistées. Revue Trimestrielle de Droit Civil; 1987.

2 Según Wim Degrave, "Basta echar una mirada a la globalización económica y notaremos la evaporación, de un momento para otro, del capital público invertido en Ciencia. Si Brasil consigue perder, en un período de 45 días, la mitad de sus reservas cambiables, no es difícil imaginar cuan fácil es trasladar de un lado para otro el capital, incluyendo también lo que es aplicado al conocimiento científico. El gran cambio es el hecho de trasladarse el desarrollo científico a la industria. La sociedad pasa a no tener ningún control sobre los productos y los procesos que están siendo llevados a cabo, pues el desarrollo científico pasa a ser controlado virtual y únicamente por grandes industrias, sin entendimiento, discusión, adaptación y absorción más igualitaria para las aplicaciones de la Ciencia". Degrave W. O poder e as responsabilidades do conhecimento científico. En: A moralidade dos atos científicos. Rio de Janeiro: Ministério da Saúde - FIOCRUZ - Fundação Osvaldo Cruz; 1999: 21
}

informado de las personas que participan en experimentos científicos. El consentimiento busca aminorar la vulnerabilidad del sujeto, al mismo tiempo que garantiza la responsabilidad de las personas implicadas en las investigaciones. El objeto principal del principio del consentimiento informado es aumentar, de acuerdo con Mark A. Hall(4), la autonomía personal de las decisiones que afectan al bienestar físico y psíquico. $\mathrm{O}$, como aseveran Bauchamp y Childrens, "la persona autónoma es la que no solamente delibera y elige sus planes, sino que es capaz de actuar con base en esas deliberaciones"(5).

Así, a título de ejemplo, al VIH ha acelerado tanto la producción de conocimiento como las discusiones sobre la ética en investigación.

El término consentimiento libre e informado ha favorecido el acceso del enfermo a cuestiones cruciales, tales como: "la justificación, el objetivo del tratamiento, si va a tener problemas con su bienestar (incomodidad), si corre riesgo, efectos colaterales, cuál es el beneficio esperado, cuál el método alternativo para aquellas investigaciones. ¿Lo que se espera es realmente mejor que aquello que ya está disponible? ¿La investigación trae algún beneficio al individuo o solamente al investigador y a la empresa? ${ }^{3}$

\section{La Bioética y el mundo jurídico}

El perfeccionamiento y el desarrollo de las nuevas tecnologías, particularmente en el campo de la biología y de la medicina, suscitaron en la opinión pública un interés renovado por las cuestiones éticas; en realidad,

\footnotetext{
El cuestionamiento aquí mencionado fue reproducido de la conferencia de Cegar Scheffer M. A experiência dos usuários - Um depoimento, proferida en la Conferencia $A$ moralidade dos atos científicos promovida por el Ministério da Saúde FIOCRUZ -Fundação Osvaldo Cruz; 1999: 111.
} 
tanto filósofos como médicos y juristas esperaban que los nuevos cuestionamientos renovarían sus disciplinas, les imprimirían una nueva dinámica $\mathrm{y}$, al mismo tiempo, estaban convencidos de que la Bioética contribuiría fundamentalmente a la pertinencia de los problemas actuales.

El mundo jurídico, que es el que nos interesa, se ha visto, de un momento a otro, requerido, tanto por los investigadores como por los profesionales que lo han invocado como medio de garantizar más seguridad y mayor legalidad a la audacia de las nuevas prácticas, evitando eventuales demandas ante los tribunales.

Pues bien, el desarrollo ilimitado de las ciencias biomédicas ha provocado reacciones en cadena, respecto de las cuales el hombre no estaba preparado, ni material ni espiritualmente hablando.

El ejemplo más evidente de lo que se está afirmando lo constituye la inseminación artificial humana. Mientras se encuentra restringida al campo médico no genera mayores cuestionamientos. Cuando, sin embargo, trasciende al mundo jurídico, provoca una infinidad de dudas, todavía no resueltas (al menos, en cuanto a la unanimidad deseada).

La inseminación artificial heteróloga, por ejemplo, ha destruido la noción, hasta entonces unívoca, de filiación ${ }^{4}$. Del mismo modo, el efecto revolucionario del análisis de ADN ha destruido la incertidumbre de la paternidad biológica, pero, a la vez, ha llevado a los juristas a repensar el problema de la paternidad afectiva (hasta entonces inimaginable).

"Priorizando lo biológico, haciendo depender la paternidad de un simple análisis

\footnotetext{
4 Ver, en este sentido, nuestro texto, Procriações artificiais e o Directo. São Paulo: Revista dos Tribunais, 1995.
}

de ADN, el legislador ha confundido y nivelado dos nociones, la de progenitor y la de padre que no son, necesariamente, concluyentes, sino que pueden presentarse separadamente, porque progenitor puede ser cualquier hombre fértil, basta manifestar capacidad instrumental para generar; padre, por el contrario, es más que un simple progenitor, puede hasta confundirse con éste, pero va más allá de la simple noción de reproducción"(6).

Como bien ha señalado Villela, con su enternecedora sensibilidad y aguda visión jurídica, "un hijo tiene que ser algo más, no simplemente un hijo"(7).

O como pretende Sullerot, "procrear no basta para ser padre, aunque el hombre reconozca ser el progenitor de un niño"(8). Lo que redunda en afirmar la diferencia que se ha establecido entre el progenitor (simple procreador) y el padre que, deseando un hijo (paternidad voluntaria no impuesta), establece una relación querida (en el acto de la generación) y mantenida en el transcurso de toda una existencia"s.

A partir de la década del 70 lo que se ha constatado ha sido exactamente eso: el desajuste, la inadecuación, cuando no la ausencia de normas capaces de responder suficientemente a las indagaciones humanas.

\footnotetext{
La paternidad y la filiación, mientras reposan sobre el hecho carnal de la procreación, tienen, seguramente, un componente biológico, pero no es el único, como aseguran, actualmente, Jean Hauser y Huet-Weiller, ni puede ser el más importante ante el Derecho; "el derecho a la filiación no es solamente el derecho a la filiación biológica, sino también es el derecho a la filiación vivida" (Hauser J, Huet-Weiler D. Traité de Droit Civil. La familla: 168) o, como bien aseveró Gérard Corou, "el derecho a la filiación no es solamente un derecho a la verdad. Es también, en parte, un derecho a la vida, al interés del niño, a la paz de las familias, a las afecciones, a los sentimientos morales, al orden establecido, al tiempo que pasa..." (Corou G. Droit Civil. La familla; vai. 2: 299).
} 
Porque el hombre no puede vivir sin límites ni reglas.

Porque el vacío jurídico hace todo posible.

No queda duda de que ha sido el desarrollo explosivo de las ciencias tecnológicas en el campo biomédico el que ha forzado la renovación de la reflexión ética y de las problemáticas que de ella proceden. Médicos y juristas, filósofos y asistentes sociales han sido compelidos a sentarse juntos para discutir una posible toma de decisión. No sólo, sin embargo, una decisión individual o restringida a un sector de indagación científica, sino, por el contrario, una decisión suficientemente amplia, capaz, en su interdisciplinariedad, de presentar una solución a toda la condición humana.

La confrontación interdisciplinaria de los casos surgidos ha suscitado, además del cuestionamiento de posturas antiguas, tenidas como ciertas, el acceso a las propuestas reales, deliberadamente innovadoras.

Gran parte de la crisis que hoy vivimos y que tratamos de manejar viene de esta constatación: el desarrollo de nuevas tecnologías al servicio de la vida o de la salud ha puesto en jaque las referencias y medidas habituales y los fundamentos de la moral y deontología que figuraban en los códigos que regulaban la conducta humana.

\section{La crisis del Derecho y la Bioética}

Introduciendo la incertidumbre en la cabecera y en la hoz de las decisiones y de las acciones, el desarrollo de las tecnologías modernas ha aniquilado los consensos y las reglas que animaban las conductas colectivas e individuales, así como las prácticas profesionales.

El ser humano -persona o colectividad- se ha tornado objeto de manipulación y ha pasado a ser, a partir de ahora, proyecto y no solamente sujeto de derecho.
El desarrollo de las nuevas tecnologías ha debilitado y, en cierta forma, ha vuelto caducas todas las antropologías que siempre han servido de parámetro a los preámbulos de la Ética y del Derecho.

Pero el ser humano, independientemente del período de evolución científica en el que eventualmente nos encontremos, sigue siendo ser humano, en su más integral y perfecta constitución. Así, los actos técnico-científicos practicados sobre el ser humano, ya sea en estado embrionario o adulto, no pueden ser considerados en niveles distintos, como pretenden ciertos segmentos científicos, o con total libertad y sin ningún control, como busca justificar el pensamiento anglosajón ${ }^{6}$.

Estos actos "son éticamente válidos cuando son hechos con el respeto y la beneficencia debidos al ser humano en cualquier nivel. Esto porque un ser humano embrionario, fetal o adulto es siempre un ser humano y nunca otra cosa; un embrión o feto humano tiene la dignidad de ser humano (o persona en potencia) éticamente más valioso que cualquiera otra especie viviente. Él posee todos los genes humanos y está en vías de llegar a ser persona... (porque) nuestro cuerpo es siempre humano en su totalidad y en cada una de sus partes... (porque) cualquiera que sea el grado de su evolución, el ser humano está situado

${ }^{6}$ La legitimidad de la Ciencia se apoya sobre fundamentos que le son propios y que provienen esencialmente de la calidad de la investigación. La libertad de la investigación es, muchas veces, considerada, especialmente en los países anglosajones, como un principio tan fundamental que justificaría una autonomía total de la ciencia en el seno de la sociedad (y que explica, actualmente, la no sumisión de Inglaterra a las reglas mundiales que prohíben la clonación humana). Según un artículo publicado en el periódico The lndependent y reproducido en el periódico Folha de São Paulo del 5 de septiembre de 2000: "Muchos de los más importantes investigadores médicos del Reino Unido creen que el nacimiento de un niño humano clonado es inevitable, a pesar de la actual aversión de la sociedad a la idea. Más de la mitad de un grupo de 32 investigadores entrevistados por The Independent ha dicho que el clon reproductivo va a ser intentado dentro de 20 años, si las dificultades técnicas y de seguridad fuesen superadas". 
en el punto más adelantado de la evolución y, por eso, revestido del grado más elevado de eticidad"(9).

Los avances biomédicos solamente han puesto al desnudo una realidad que desde hace mucho tiempo se hacía necesario revelar: en una sociedad pluralista y secular los referentes religiosos y las escalas de valores no son más objeto de consenso suficiente, incluso en materias capitales, tales como el sentido de la vida y de la muerte.

Y la Bioética ha intentado, precisamente, abrir nuevos caminos a la discusión y a la toma de decisión en este contexto secular y pluralista.

Los riesgos y, más ampliamente, las expectativas sociales vinculadas a la utilización de tecnologías, han hecho resaltar la responsabilidad de los científicos, haciendo creer que una información rigurosa y permanente de la opinión pública hará posibles los debates, creándose organizaciones pluridisciplinarias de orientación (comités de ética, por ejemplo) y de decisión (consejos interdisciplinarios, tribunales nacionales e internacionales) en los cuales tomarán asiento, lado a lado, legos y especialistas, todos asociados como verdaderos compañeros del Derecho.

¿A quién corresponde decidir y discutir acerca del "bien" y el "mal" de las nuevas conquistas? ¿A quién corresponde decidir sobre la vida y la muerte? ¿Quién va a decidir y en virtud de qué autoridad, la humanidad que seremos mañana?

Desde luego no corresponde a los biólogos ni tampoco a la Bioética contestar las preguntas planteadas, ni decidir lo que será la humanidad del mañana. La Bioética puede, sin embargo, invitar, convocar, estimular y ayudar a los buenos espíritus a discutir todas esas materias.

¿Y cuál es el papel reservado al Derecho?
¿Es legítima la creación de normas específicas para regular estas materias?

Algunos invocan leyes para justificar sus prácticas biomédicas, para evitar demandas judiciales y eliminar interpretaciones comprometedoras. Otros piden leyes para prohibir ciertas prácticas consideradas excesivas o socialmente inaceptables.

Se habla frecuentemente de vacío jurídico como si se tratara de una catástrofe. En efecto, sin ley, nada está fuera de la ley y todo es posible.

¿Por qué serían necesarias leyes respecto de estas materias? Porque el Derecho implica valores. Quiérase o no, esta conclusión es inevitable. No se puede tener un conjunto de leyes que no repose sobre ciertos valores. Por lo menos, sobre ciertos valores dominantes en la sociedad.

Por eso la ley es siempre invocada; no solamente porque las leyes sirven como "medios" ante las finalidades que son los valores, sino, sobre todo, porque su ocurrencia es expresión incuestionable de seguridad, de límites, de los valores comunes de la comunidad que siente necesidad de su determinación por vía normativa, como parámetro de conducta observable por todos. Porque el Derecho busca organizar la conducta de cada uno en el respeto y promoción de los valores que sirven de base a la civilización.

\section{EI desarrollo de la ciencia y la necesidad de control}

El Derecho, seguramente, debe intervenir en el campo de las técnicas biomédicas, para legitimar unas, para prohibir o reglamentar otras.

Se trata, en la visión del ya mencionado Volnei Garrafa, de estimular el desarrollo de la ciencia dentro de sus fronteras humanas y, a la vez, de desalentarla cuando avanza en dirección de límites inhumanos y iatrogénicos. 
En efecto, la inviolabilidad del cuerpo humano y su misma definición se encuentran, actualmente, amenazadas por las excepcionales manipulaciones técnicas generadas por el desarrollo de la investigación científica y favorecidas por las "lógicas" que Marie-Thérèse Meulders-Klein ha agrupado en cuatro grandes categorías: a) la lógica del conocimiento y del poder; b) la lógica del provecho; c) la lógica de la búsqueda de la felicidad; y e) la lógica de la utilidad.

La primera, según la sensible civilista belga, es privilegio del mundo racional occidental y se materializa en la voluntad ininterrumpida de saber el "cómo" y el "porqué" de las cosas para mejor dominar la naturaleza y, con ella, el destino. El hombre occidental es llevado adelante en la investigación de una verdad que, ciertamente, nunca va a ser alcanzada; un mundo que busca combatir la finitud humana subordinando la naturaleza a sus necesidades y deseos.

La lógica del provecho es mucho más grave en la medida que todo avance científico provoca inmediatamente un instinto profundamente enraizado en el hombre: el del lucro y el provecho.

En un mundo volcado a la economía de mercado, biotecnologías, nuevos aparatos, nuevos productos, de origen humano o no, siempre han suscitado atracción por lucrar, y no solamente en las empresas, como se podría pensar, sino también en los intermediarios poco escrupulosos y, más simplemente, en los que están bajo presión por las necesidades económicas (lo que nos hace pensar en la venta de órganos, de tejidos, en el arriendo de úteros, etc.) constreñidos a venderse o arrendarse para satisfacer el interés de los más ricos.

En este sentido, la actual discusión sobre la posibilidad de patentar genes (léase, la vida humana) forma parte de la lógica del mercado.
Mientras que en Estados Unidos ya fueron concedidas patentes para más de mil genes humanos, es decir, independientemente de cualquier objeción ética, las decisiones están siendo tomadas en un nivel puramente técnico, en Europa hay una enorme controversia y Francia -que ha prohibido las patentes de genes- lucha contra una directiva de la propia Comunidad Europea, que es favorable.

En Brasil, la Ley de Propiedad Industrial, que rige las patentes, prohíbe cualquier posibilidad de patentar genes humanos ${ }^{7}$. Es decir, la Ley 9.279/96 es suficientemente clara para alejar cualquier comentario favorable a la posibilidad de patentar genes humanos; como se encuentran en la naturaleza, no se puede patentar genes humanos ni genes de plantas (seres vivos naturales), en la medida en que la ley prohíbe la hipótesis de patentar seres vivos en todo o en parte (y el ADN es considerado parte), incluyendo genoma o germoplasma que se encuentran en la naturaleza o de ella son aislados.

La tercera lógica - la búsqueda de la felicidad - no es tan mercantil como las demás, pero, como asegura Meulders-Klein, también se somete a las leyes del mercado. Ella no se refiere a la oferta, sino a la búsqueda. Aunque menos poderosa que las demás, constituye igualmente motor para la ciencia.

Si los investigadores buscan y siempre encuentran nuevas propuestas para el Hombre es porque, desde tiempos inmemoriales, la voluntad de combatir el sufrimiento y la muerte, así como una sed inagotable de felicidad, persiguen constantemente a la voluntad humana.

Así ha ocurrido con la contracepción, cuya necesidad existía mucho antes de la píldora. Pero,

El art. $10^{\circ}$ dispone: "No se considera invención ni modelo de utilidad (...) IX- el todo o parte de seres vivos naturales y materiales biológicos encontrados en la naturaleza, o todavía que de ella aislados, incluso el genoma o germoplasma de cualquier ser vivo natural y los procesos biológicos naturales." 
por un curioso fenómeno, la satisfacción de las necesidades fomenta la demanda y no tolera el fracaso. De ahí los pedidos de interrupción del embarazo, como último correctivo o sustituto contraceptivo. Es allí donde la ciencia se revela impotente frente al sufrimiento que surge el auxilio efectivo para morir, que también va a ser solicitado por el hombre como recurso legítimo.

En otros términos, la eutanasia como derecho.

Y los ejemplos se multiplican: la facultad, inusitada y sin precedentes en la historia de la humanidad, de fecundar un óvulo fuera del útero materno, de preservar a los gametos por medio de la crioterapia, de manipular los genes, de manipular el genoma de un óvulo humano fecundado, y ahora... la clonación; todo eso ha generado desafíos ilimitados, pero también reivindicaciones no menos desmesuradas a las cuales, sabios, médicos y juristas son llamados a contestar, así como el propio Estado.

Finalmente, la lógica de la utilidad. Es la lógica del Estado frente a la demanda de los hombres, ya se trate del Estado totalitario o del Estado benefactor, confrontado a costos de tratamientos excepcionales.

Aquí las motivaciones se han hecho ambiguas, pues, si la investigación puede aminorar o hasta erradicar muchas enfermedades, los medios sofisticados que ella desencadena o que ella exige para realizar ciertos tratamientos son tan caros y la prolongación de la esperanza de vida tan onerosa, que un proceso de racionamiento de gastos ya ha sido desencadenado en diversos países del mundo.

Y, otra vez, estaremos frente a nuevos dilemas éticos, económicos y jurídicos.

Todos los países occidentales se encuentran, actualmente, confrontados con estos problemas. Unos, en mayor escala, otros, en proporciones más reducidas, pero el problema está siempre presente.
Y la Bioética es la ciencia que ha nacido de todos estos cuestionamientos.

Ella no se refiere directamente a la cuestión de las normas, pero en cuanto reflexión sobre las cuestiones éticas levantadas por los problemas, ella provoca en su esfera la cuestión de “¿qué hacer?”, es decir, ¿cómo asegurar el dominio social de la producción, difusión y utilización de las nuevas tecnologías de vida?

Y además de eso, ¿qué nueva concepción de hombre deberá consagrarse socialmente?

\section{La insuficiencia de las reglamentaciones alternativas}

En espera de una posición firme y objetiva del legislador, la mayoría de los países ha recurrido a las reglamentaciones que hoy son de cuatro tipos:

a) los códigos de deontología profesional;

b) los reglamentos que se imponen ciertas asociaciones;

c) las reglas de conducta establecidas por ciertas instituciones particulares;

d) las orientaciones de los comités de ética ${ }^{8}$.

Estas reglas no tienen la misma naturaleza, pero todas ellas se presentan como alternativas de una legislación estricta. Queda saber cuál es su valor, su legitimidad y pertinencia.

Dos serían básicamente las críticas que se podrían levantar contra estas alternativas.

\footnotetext{
En Brasil, el principal instrumento de trabajo de los CEPs (Comités Especiales de Investigación) es la Resolución 196/ 96 del Ministerio de la Salud, que no es una ley dotada de poder de fiscalización y punición, sino un instrumento cuya fuerza normativa y prescriptiva depende de su poder de convencimiento. Los pareceres emitidos por los CEPs son el resultado de una decisión colegiada y, contrariamente al modelo francés (como es el Comité Consultatif National d'Éthique, cuya totalidad de miembros debe leer todos los proyectos recibidos y emitir un parecer), en el caso de los CEPs brasileños, cada proyecto es analizado por lo menos por dos miembros, siendo, en seguida, discutido en el plenario del CEP (que ocurre mensualmente).
} 
Primero, estas reglamentaciones son ineficaces, están desprovistas de cualquier obligatoriedad, pueden ser fácilmente modelables y, por lo tanto, no permiten alcanzar el objetivo buscado.

Así, para mencionar el ejemplo del caso brasileño, los códigos de deontología médica -como ocurre en Brasil con la Resolución número 1.358/92, del Consejo Federal de Medicina (que adopta Normas Éticas para utilización de técnicas de reproducción asistida)- vinculan a todos los miembros (cuerpo médico) de la profesión, sin excepción.

Pero estas normas están desprovistas de juridicidad y, por tanto, no abren espacio a reales recursos frente al orden jurídico. Un enfermo hasta puede cuestionar la conducta de un médico frente al Consejo Federal de Medicina, por ejemplo, pero la queja formalizada va a producir, como mucho, una sanción de orden disciplinario: reprensión, suspensión temporaria o, excepcionalmente, exclusión del cuadro médico.

De cualquier manera, una reparación por daños, seguramente, nunca se va a producir en base a una regla de conducta prevista en el código deontológico.

En el mismo sentido, las reglas propias de las asociaciones, de las instituciones o de los comités de ética, en su campo de acción quedan restringidas exclusivamente al órgano emisor de la norma, no tienen el aval del poder legislativo, luego, su campo de acción ya nace limitado.

En el caso de la resolución brasileña número $1.358 / 92$, por ejemplo, una mujer soltera puede someterse al proceso de inseminación artificial y generar un hijo sin padre, cuando es sabido que la familia que el legislador tiene interés en garantizar al niño es la formada por padre y madre; cuando es regla dominante en la ética mundial contemporánea no admitir el recurso a la procreación artificial movido por puro egoísmo o por simple interés de orden particular, sino siempre como resultado de un proyecto de padre y madre (de la pareja, por lo tanto) tendiente a modelar los problemas derivados de la infertilidad o de la esterilidad humanas.

Evidentemente esta es una materia que va a exigir la inmediata actuación de una norma legal (dotada de obligatoriedad, pues) en sustitución a una regla deontológica, de manifiesto interés de una categoría profesional (en este caso, los médicos).

Y la prueba de que esto es posible ya es visible en diversas propuestas europeas.

Así, en Francia, según nos informa Brigitte Le Mintier(10), el legislador ha roto con la práctica antigua que hacía depender la asistencia médica a las procreaciones de las reglas deontológicas (es decir, dictadas por intereses del cuerpo médico) y la ha colocado bajo la égida de la regla jurídica. O sea, a partir de ahora, el médico solamente puede practicar inseminaciones artificiales en los casos enumerados por la ley.

Enseguida, la ley ha definido las condiciones de acceso a la asistencia médica en cuanto a la procreación, alejando la pretensión de ciertos usuarios (movidos por intereses estrictamente personales). $\mathrm{O}$ sea, el legislador ha desplazado la materia de las procreaciones artificiales del terreno de los derechos subjetivos (en el sentido de que los individuos no tienen un derecho subjetivo de invocar la asistencia médica a la procreación) para integrarla en el derecho objetivo.

Matiz simple, pero imantado de significaciones. La Ley del 29 de julio de 1994 fue todavía más lejos, definiendo -entre las operaciones realizables teniendo en vista los 
avances de la ciencia- aquéllas que el médico puede efectuar con vistas a una procreación fuera del proceso natural. Así, ha quedado definido por la nueva ley que el médico solamente puede prestar su auxilio cuando la propuesta es de la pareja y atiende a un proyecto de los padres, en dos casos: remediar la infertilidad de la pareja o evitar la transmisión de una enfermedad grave al niño por nacer.

El legislador ha tomado una posición clara y no permite más que las condiciones de acceso a las procreaciones artificiales sean decididas por el juez, por los médicos o por las partes interesadas. Es la ley quien define las condiciones de acceso.

La nueva legislación restringe la asistencia médica a la procreación a los únicos (dos) casos que ella indica en el texto legal y marca, así, un límite al desarrollo de la medicina que se puede calificar de "medicina del deseo". El médico no está disponible para realizar los deseos diversos y fantasiosos de sus clientes.

Pero la nueva tendencia legislativa produce efectos más amplios de los que se puede imaginar en un abordaje inicial y superficial.

En efecto, al definir el ambiente de la actividad médica, el legislador saca la relación médica de la esfera privada. El acto médico deja de ser una relación entre dos personas privadas. La oferta hecha por la ley y legitimada por el médico pasa a ser limitada por aquello que el legislador considera "éticamente" posible. Lo que es científicamente posible se encuentra socialmente limitado.

La pregunta de Francisco Amaral: "¿todo lo que es técnicamente posible lo es ética y jurídicamente?" $4, p .35)$ ya encontraría en la postura francesa una respuesta inmediata y sin vacilaciones: todo lo que es técnicamente posible no lo es, necesariamente, ética y jurídicamente. Si todos los avances son benéficos ya que el conocimiento de las cosas nada más es que un "plus", el empleo hecho por los hombres debe ser controlado, bajo el riesgo de practicarse actos antijurídicos y antiéticos.

Paralelamente a la limitación de los poderes de los médicos (hasta entonces, totales), el legislador francés ha restringido -y de cierta manera suprimido- el poder del enfermo de solicitar asistencia médica a la procreación.

Así, a través de la aplicación del artículo L.152-2 línea 2 del Código de Salud Pública, solamente pueden beneficiarse las parejas heterosexuales casadas o que han tenido vida en común a lo menos por dos años.

Dos argumentos esenciales fueron invocados por el legislador de la época para justificar esta eventual intromisión del Estado en la esfera privada: el primer argumento está vinculado con el derecho al respeto de la vida privada de las personas y, más precisamente, con el derecho al respeto de la vida familiar y con el derecho a crear una familia. Estos distintos derechos, que traducen la libertad de la persona de organizar su vida personal, confirieron, bajo la óptica de algunos juristas, un "derecho al niño" que, seguramente, acarrearía el libre acceso a la asistencia médica en cuanto a las procreaciones. El invocado "derecho al niño" obligaría al Estado a poner a disposición de todo individuo las técnicas de procreación artificial.

Así, aunque esta intención dependiese de un deseo, de una pulsión o de un fantasma, ella debería ser atendida.

Pues bien, este tipo de raciocinio fue literalmente descartado por el legislador de 1994.

Así, asumiendo una postura diametralmente opuesta, el legislador del 94, invocando el 
mismo derecho al respeto de la vida, entiende que este derecho solamente puede ser alegado cuando la vida íntima de la persona que lo invoca solamente dice relación con ella.

Ahora bien, en el caso de la procreación, la vida y el derecho de otra persona están en juego: los del niño.

El derecho al respeto de la vida privada, derecho egoísta, no puede ser invocado por su titular para destruir o comprometer los intereses de otro individuo (en este caso, del niño).

Estos distintos derechos individuales no pueden transformarse en un derecho a tener un hijo. El interés mayor del niño (tan invocado por el ECA, y cotidianamente comprometido) permite un control de la institución familiar y autoriza al Estado a penetrar en la esfera privada de los individuos, traspasando hasta la intimidad, si fuese necesario, porque la protección del niño constituye una exigencia de toda la sociedad democrática y el fundamento de la ingerencia estatal en la vida privada.

En materia de asistencia médica, como asegura Feuillet-le-Mintier, conviene alejar cualquier raciocinio en términos de derechos subjetivos. Si la procreación está vinculada a la vida privada de la madre, ella está igualmente vinculada a la vida de otro individuo: el niño por nacer. Ahora bien, la necesaria protección del niño en general y del niño por nacer en particular, exige que se abandone el terreno de los derechos subjetivos para situarse sobre el terreno del derecho objetivo.

Además, toda la jurisprudencia actual en materia del derecho a crear una familia o del derecho al respeto de la vida familiar demuestra que los juzgadores vinculan estas nociones a aquélla de "vida familiar normal", entendiéndose por "normal" aquello que es política y socialmente -desde el punto de vista predominante- considerado como tal. Si esta noción no puede hoy ser entendida como referencia expresa al matrimonio o a la familia legítima, ya que la nueva Constitución ha rechazado el modelo familiar único (vía reconocimiento de las entidades familiares), ella aún es válida para la relación padres-hijos, dado que todo niño tiene derecho ${ }^{9}$ a la convivencia familiar (de padre y de madre) y la psiquiatría siempre ha afirmado de manera taxativa que la identificación paterna y materna es fundamental para el desarrollo normal de los seres humanos ${ }^{10}$.

El segundo argumento, como nos informa Feuillet-le-Mintier, invocado para criticar la intervención del legislador en la relación privada médico-enfermos, es el de que el acceso a la asistencia médica es libre para todos los individuos y que su objetivo es el cuidado del enfermo. En realidad, en el caso de las procreaciones artificiales, el argumento es improcedente en la medida que la intervención médica no tiene como objetivo tratar la esterilidad de uno de los miembros de la pareja, sino atenuar la ausencia de hijos.

Cabe resaltar que el fundamento de la intervención estatal es y debe ser el interés del niño. La necesaria protección del niño por nacer exige que se abandone el terreno de los derechos subjetivos para poner las procreaciones artificiales bajo la égida del derecho objetivo.

\footnotetext{
El nuevo texto constitucional es clarísimo en cuanto al derecho del niño a la convivencia familiar cuando, en el art. 227, así dispone: "Es deber de la familia, de la sociedad y del Estado asegurar al niño y al adolescente, con absoluta prioridad, el derecho a la vida, a la salud, a la alimentación, a la educación, al ocio, a la profesionalización, a la cultura, a la dignidad, al respecto, a la libertad y a la convivencia familiar $y$ comunitaria, además de ponerles a salvo de toda forma de negligencia, discriminación, exploración, violencia, crueldad y opresión". (Subrayamos)

10 Según Françoise Dolto: “Más vale que el niño diga: 'Tengo tres padres', que diga 'Mamá vive sola, no tengo padre'; y más adelante: "el lugar donde aprende a encontrar seguridad en la sociedad es en la presencia de los padres, que son los garantes de su identidad". (Dolto F. Quando les parents se séparent. Paris: Seuil;75-00.)
} 
O, como tan bien ha subrayado Feuillet-leMintier, "nuestro sistema francés de respeto a la vida privada no puede ser asimilado al sistema americano del right of privacy por el cual toda persona tiene el derecho de asumir sola las decisiones en la esfera de su vida privada"11. Es interés de todos (interés general) proteger a los niños $\mathrm{y}$, especialmente, a aquéllos a los que la sociedad va a ayudar a nacer.

Además, el artículo 3 de la Convención Internacional de los Derechos del Niño se coloca en la misma dirección. El texto del artículo mencionado dispone que en toda decisión concerniente al niño, el interés superior de él debe ser una condición primordial. En nombre del interés del niño, el Estado puede tomar medidas protectoras, especialmente, reglamentar el acceso a las procreaciones artificiales. Esto ha sido lo que el legislador del 94 ha hecho y sin vacilaciones.

La legislación francesa de 1994 descansa sobre la idea de que la sociedad auxilia a las parejas infértiles, a través de la asistencia médica, garantizando al niño por nacer un doble parentesco: el del padre y el de la madre. "La Ley -como informa Feuillet-le-Mintierquiso seguir el 'curso natural' de los hechos: dos padres heterosexuales aún hoy es lo mejor para el niño"(10).

El ejemplo de la legislación francesa, aunque restringido a un sector específico de las procreaciones artificiales, merece amplia reflexión y análisis porque refleja de manera precisa, objetiva y segura, la intervención del

\footnotetext{
${ }_{11}$ Principio considerado como constitucional por la Corte Suprema de los Estados Unidos en 1965 (381 US 479, 485) Según la postura doctrinaria e ideológica norteamericana, cada persona es soberana en esta esfera privada, soberana especialmente en relación con el Estado y a las autoridades públicas. Le Mintier BF. L'assistance médicale à la procréation. In: Les lois "bioéthiques" à l'épreuve des faits. Réalités et perspectives. Paris: PUF; 1999.
}

legislador en un sector que, desde hace mucho, exigía control tendiente a evitar abusos de naturaleza personal y carácter egoísta, contrarios a la noción mayor (ética y jurídica) de la efectiva protección del interés superior del menor.

De la misma forma, y con mucha razón, las discusiones más recientes en el mundo europeo han cuestionado el valor de las decisiones tomadas por los comités éticos. Preguntan algunos: ¿Qué más da la prohibición de determinadas técnicas -como la de crear clones humanos- si los investigadores, en sus laboratorios, son libres para actuar conforme a sus intereses y curiosidades de investigación?

En un segundo momento, las críticas han tomado otro curso: además de ineficaces, las reglamentaciones serían antidemocráticas. Es decir, estas reglamentaciones impuestas por determinados segmentos profesionales no representarían el interés del cuerpo social en su totalidad, no corresponderían a las propuestas sacadas de un debate público, como ha ocurrido, por ejemplo, con la legislación sueca relativa a las procreaciones artificiales.

Además, estas reglamentaciones serían injustas, toda vez que ellas no son necesariamente uniformes en todos los países. Ellas pueden hasta diferir considerablemente de un país a otro. Y esto genera una importante cuestión de justicia social. A modo de ejemplo, en Alemania el Informe Brenda prohíbe cualquier experiencia sobre el cuerpo humano, pero en la frontera entre Alemania y Francia, en Estrasburgo, los alemanes pasan a diario a Francia en búsqueda de clínicas de inseminación artificial.

Todo indica, pues, que una legislación suficientemente flexible, pero tenaz, debe ser creada para controlar y reglamentar cuestiones que, desde hace mucho, están reclamando una regulación en la sociedad. 
En efecto, nunca la intervención legislativa ha sido tan deseada como en la actualidad, pero, contradictoriamente, temida por los juristas, científicos, médicos y moralistas que se preocupan con la multiplicación de situaciones totalmente fuera de las normas, generadas por técnicas cada vez más sofisticadas de manipulación de la vida y de la muerte.

Y este desajuste entre lo real y lo ideal, entre lo vivido y lo deseado, nos lanza al terreno de la duda, de ahí el caos y la amarga sensación de impotencia que acompañan irremediablemente al Hombre en el final del siglo.

Y la duda nos conduce a otro tipo de indagación: ¿Qué normas deben ser creadas?

\section{La Resolución 1.358/92 del Consejo Federal de Medicina de Brasil}

La resolución número 1.358/92 del Consejo Federal de Medicina (Brasil), que ha adoptado Normas para la Utilización de las Técnicas de Reproducción Asistida, todavía en vigor, se divide en 7 secciones, a saber: 1) Principios Generales; 2) Usuarios de las Técnicas de RA (reproducción asistida); 3) Clínicas, Centros o Servicios que ponen en práctica las técnicas de RA; 4) Donación de gametos o pre-embriones; 5) Preservación de gametos o pre-embriones a través de crioterapia; 6) Diagnóstico y tratamiento de pre-embriones; 7) Gestación de sustitución (donación temporal del útero).

La Resolución brasileña ha seguido la tendencia europea (con excepción de Inglaterra), cuando elaboró un conjunto de disposiciones éticas relativas al donante, a la pareja y al médico. Las reglas de gratuidad, anonimato y consentimiento informado fueron debidamente previstas en la Resolución mencionada.

Así, en la Sección IV, número 1 se establece que: "La donación nunca va a tener carácter lucrativo o comercial". La noción proviene del principio fundamental según el cual el cuerpo humano, en todo o en parte, no puede ser objeto de comercialización. Además de la consideración simplemente ética, la Constitución Federal Brasileña prohíbe cualquier comercialización de órganos, tejidos y sustancias humanas (leche, sangre y esperma) sea para transferencia, investigación o tratamiento (Art. 199, § $4^{\circ}$ ).

Además, en un país que, a pesar del espectacular desarrollo industrial, todavía presenta segmentos sociales pobres, la prohibición de la comercialización protege a los menos favorecidos de decisiones precipitadas o insuficientemente reflexionadas y que podrían verse atraídos por el interés financiero inmediato, de resultados posteriores lamentables. Como ha subrayado el CECOS francés, "la no retribución tiene la ventaja de valorizar socialmente la donación de esperma"(11).

Así, aunque reconociendo que "d'une manière générale le droit témoigne d'une grande méfiance, voire, d'une certaine hostilité à l'égard des opérations sans contrepartie"(12), no queda duda que, en materia de procreaciones médicamente asistidas, además de su valor simbólico, la gratuidad presenta ventajas médicas ciertas (facilita las investigaciones genéticas y médicas, ya que ningún interés pecuniario conduce al donante potencial a enmascarar eventuales problemas de salud) y beneficios psicológicos (la existencia de donantes remunerados provoca consecuencias importantes en el significado de la donación).

La Resolución brasileña prevé (en el número 2 de la Sección IV) que "los donantes no deben conocer la identidad de los receptores y viceversa". Si el Consejo Federal de Medicina erigió el anonimato como regla, esto se debe a una opción intencional hecha para proteger al niño, con el fin de que no se torne en víctima de problemas que puedan surgir entre el donante 
y los padres usuarios de la inseminación artificial.

El anonimato protege a la pareja y al niño contra eventuales pretensiones del donante y este último queda protegido contra la búsqueda de su identidad. Sin embargo, como ya ha sido afirmado por algunos segmentos de la doctrina jurídica brasileña -opiniones minoritarias, pero tenaces- el anonimato debe ser prohibido, por lo menos, en cuanto al establecimiento de la filiación con relación al donante.

$\mathrm{Si}$, hasta ahora, el anonimato fue el principio fundamental y dominante en Brasil, actualmente se tramita en el Senado un proyecto de ley (número 90/1999) que prevé la supresión del anonimato en los siguientes términos:

"El niño tendrá acceso, directamente o por medio de un representante legal, a todas las informaciones sobre el proceso que lo ha generado, incluso la identidad civil del donante, en los casos autorizados en esta ley, obligándose el establecimiento responsable del empleo de la $R A^{12}$ a proporcionar las informaciones solicitadas".

Seguramente, la experiencia de las leyes española e inglesa, que prevén la posibilidad del niño de acceder, en su mayoría de edad, a las informaciones genéticas que no identifiquen a su progenitor biológico, ha jugado aquí un papel decisivo. De cualquier manera, esta nueva tendencia es tan reciente que nos encontramos aún lejos de alcanzar y de ofrecer en el plano jurídico (biomédico, psicológico o ético) soluciones razonables y aceptables para todas las partes en juego.

Igualmente, el consentimiento informado está previsto en la Resolución brasileña, cuando

\footnotetext{
${ }^{12}$ Reproducción asistida (lo mismo que reproducción médicamente asistida).
}

trata de los Principios Generales, en los siguientes términos:

"El consentimiento informado será obligatorio y extensivo a los pacientes infértiles y donantes. Los aspectos médicos relativos a todas las circunstancias de aplicación de una técnica de RA serán detalladamente expuestos, así como los resultados ya obtenidos en aquella unidad de tratamiento con la técnica propuesta. Las informaciones deben también comprender datos de carácter biológico, jurídico, ético y económico. El documento de consentimiento informado constará en formulario especial y contendrá el acuerdo, por escrito, de la paciente o de la pareja infértil".

Ya sea que se trate de países subdesarrollados, desarrollados o en vías de desarrollo, es importante consagrar tiempo y atención para explicar con precisión a los futuros pacientes y, cuando sea necesario, a sus compañeros, los detalles del tratamiento de la esterilidad que ellos van a enfrentar. Como ha precisado el Informe Warnock, "el consentimiento por escrito de dos compañeros debe ser obtenido, si es posible, antes del inicio del tratamiento, a título de buena práctica"13.

Es la fórmula adoptada por la Resolución brasileña y que corresponde a uno de nuestros principios generales: la obtención de un consentimiento informado, libre y claro antes de cualquiera intervención de naturaleza médica sobre el ser humano.

El análisis de la Resolución 1.358/92 revela, sin embrago, la ocurrencia, por lo menos, de dos puntos controvertidos que suscitaron vivas reacciones en diversos sectores de la sociedad brasileña.

\footnotetext{
${ }^{3}$ Informe de la Comisión de Investigación presidida por Mary Wamock -Fécondation et embryologie humaine- fies. Paris: La Documentation Française; 1984: 33.
} 
El primero se refiere a la cuestión de la inseminación artificial de mujeres solteras y, el segundo, al futuro de los embriones excedentes.

En efecto, dirigiéndose a los "Usuarios de las técnicas de RA”, la Resolución genera la rara sensación -contraria al nuevo texto constitucional, como vamos a ver- de permitir el acceso de las mujeres solteras a las RA sin ninguna restricción. El número 1 de la Sección II (Usuarios de las técnicas de RA) dispone que:

"Toda mujer capaz, en los términos de la ley, que lo solicite y cuya indicación no se aparte de los límites de esta Resolución, puede ser receptora de las técnicas de RA, siempre que lo haya acordado de manera libre y consciente en documento de consentimiento informado".

Refiriéndose a las "mujeres capaces", la Resolución no ha prohibido el acceso de las mujeres solteras a las RA, lo que implica negar la dualidad de los padres, en este caso, la paternidad. Ahora bien, en la medida que la Constitución Federal protege, en su artículo 227 , el derecho del niño a la "vida familiar" (es decir, el derecho a la identificación de sus dos progenitores, el padre y la madre) esta posibilidad es seguramente ilegítima, pues es contraria al interés del niño cuyo nacimiento fue programado, deliberadamente, sin padre. Además, esta hipótesis corresponde a una agresión a los derechos del niño, ya que la creación de familias monoparentales (con un solo progenitor) es contraria a la evolución del derecho de la filiación que, levantando las interdicciones que se referían a los hijos naturales, ha favorecido el derecho de todo niño a tener una filiación paterna.

En efecto, de acuerdo con lo señalado anteriormente, "las RA no corresponden a un proyecto personal y egoísta, sino más bien a un proyecto relacionado con el parentesco. Por lo tanto, frente al riesgo de quedar sin padre, mejor es prohibir el acceso a proyectos de reproducción asistida a estas categorías individuales"(13).

Ahora bien, es evidente que una mujer soltera inseminada no está en condiciones de garantizar -por más bien intencionada que esté- el patrón familiar (constituido de padre y madre) que naturalmente ocurre en una comunidad familiar.

Pretender el nacimiento de un niño huérfano es contrario a la más elemental noción de derecho natural y de orden público.

Este debate ha provocado vivas controversias en Brasil, en la medida que él invoca cuestiones cuya solución depende de las costumbres, de la ética y del Derecho. Sin embargo, la opinión mayoritaria entre los brasileños, prudentemente, busca evitar un mal mayor: garantizar, por lo menos, un padre al niño.

Cabe resaltar que, como el Estatuto del Niño y del Adolescente (ECA) predica siempre el interés mayor del niño, no queda ninguna duda de que no se puede aceptar la inseminación de mujeres solteras.

En cuanto a los embriones excedentes, la Resolución ha optado por una fórmula que no es suficientemente nítida y que ha generado una serie de vacilaciones exegéticas.

Así, los números 2 y 3 de la Sección V (Conservación de gametos o pre-embriones) disponen:

"El número total de pre-embriones producidos en laboratorio será comunicado a los pacientes, para que se decida cuántos pre-embriones serán transferidos de inmediato, debiendo el excedente ser preservado por 
crioterapia, no pudiendo ser descartado o destruido.

En el momento de la preservación por crioterapia, los cónyuges o compañeros deben expresar su voluntad por escrito, en cuanto al destino que se dará a los pre-embriones preservados por crioterapia, en caso de divorcio, enfermedades graves o fallecimiento de uno de ellos o de ambos, y cuando desean donarlos".

Las dos disposiciones generan una de las cuestiones más controvertidas y más complejas, ya que las incertidumbres del pensamiento técnico sobre lo que es un embrión humano con relación a una persona humana, aún no autorizan la elaboración de reglas concretas e indispensables.

De cualquier forma, la Resolución arriba mencionada no resuelve el impasse creado por el tiempo de falta de desarrollo que media entre la fecundación in vitro y el reimplante en beneficio de los progenitores.

La duda mayor que inquieta a los especialistas es la de saber si la Resolución prohíbe efectivamente la destrucción de los pre-embriones (como se señala al final del número 2) o, por el contrario, si es posible destruirlos, si consideramos la expresión “... los cónyuges o compañeros deben expresar su voluntad por escrito..." (número 3 de la Resolución).

El problema sigue siendo siempre el de determinar el futuro de los embriones cuando la pareja rompe su relación o cuando uno de los miembros muere o, sencillamente, si surgen divergencias en el seno de la pareja; ¿a quién pertenecerá el poder de decisión? ¿A uno solo de los cónyuges? Y si no existe más un proyecto parental, ¿al organismo que conserva los embriones cabría asumir la responsabilidad por sus destinos?
El estatuto del embrión reposa en el centro de la problemática surgida por el congelamiento, ya que las respuestas dadas a estas preguntas cruciales provienen directamente de la definición de este estatuto.

Estas cuestiones iniciales son suficientes para determinar la importancia de la Bioética en materia de reglamentación y su efecto en el mundo jurídico.

\section{Conclusión}

Las cuestiones relativas a la Bioética están, naturalmente, llenas de complejidad porque, al contrario de otras áreas del conocimiento, que pueden agotarse bajo una visión reduccionista, son también cuestiones científicas, filosóficas, económicas y jurídicas. La interdisciplinaridad es la tónica.

Por otro lado, el Derecho, como norma imperativa, ha encontrado gran dificultad en reglamentar las investigaciones y las técnicas biomédicas a través de las leyes bioéticas, porque sigue concurriendo con otros sistemas normativos no oriundos de los poderes públicos, sino originarios de la comunidad científica (como es el caso de las legislaciones alternativas, arriba mencionadas).

"Frente a la legitimidad democrática concluye Mathieu(14)- se construye una legitimidad oligárquica, de los sabios, de los técnicos, de los estudiosos. La afirmación según la cual corresponde a los poderes públicos, emanación de la sociedad política, regir la actividad científica y las práctica médicas, no es evidente. El Derecho debe primeramente establecer la legitimidad de su intervención en estas materias".

Las preguntas cruciales que interfieren en la invocada legitimidad siguen siendo: ¿El Derecho de la Bioética puede adaptarse al molde de los principios generales del Derecho 
Civil o se inscribe en la lógica de los derechos fundamentales, entendido como un nuevo sistema de derecho? Cuando se toca al hombre y a su esencia, ¿el derecho natural tiene algo que decir en la esfera de un sistema positivista? ¿Por qué las autoridades públicas deberían controlar la actividad científica y las prácticas biomédicas?

He aquí algunas cuestiones que han desafiado la argucia de los estudiosos y de cuyas respuestas depende la legitimidad de la interferencia jurídica en materia biomédica.

Un aspecto fundamental y que no puede ser subestimado: la idea de que el Derecho puede imponerse por sí solo en esta esfera es totalmente ilusoria. Y todos los intentos de simple imposición de la norma, pura y simple, sin involucrar a otros interesados en la conclusión de las complejas cuestiones, se han revelado insuficientes y han tendido a ser simplemente desconsiderados.

La existencia y el papel desempeñado por los comités de ética ya han demostrado que el Derecho no puede imponerse por sí mismo; o sea, la legitimidad jurídica es mediatizada por el debate con los científicos. El Derecho se construye en relación con sus descubrimientos, pero también a partir de los riesgos que las nuevas técnicas crean para la condición humana. Es la interferencia de dos mundos, el científico por un lado (léase, biomédico) y el jurídico, por otro, que, a través de un proceso lento, tardío y cauteloso, va determinando conductas, posturas y eventuales sanciones aceptadas por toda la comunidad humana.

En relación con los riesgos científicos originados por los nuevos descubrimientos y por las nuevas tecnologías, la experiencia ha demostrado que las normas de la Bioética son, primero, normas deontológicas o éticas dictadas por las organizaciones representativas de los científicos y de los médicos- para, solamente en un segundo momento, ingresar en el terreno jurídico, en la esfera de la norma imantada de obligatoriedad.

La autonomía jurídica que siempre ha caracterizado a la construcción del Derecho se ve, por primera vez en la historia de la humanidad, transferida a una posición secundaria, situación inédita cuya ocurrencia ningún jurista pudo prever.

Pero, a despecho del desnivel "inicial" que acompaña el proceso de legitimidad o de transposición de la exigencia ética a nivel normativo, las normas deontológicas o éticas mantienen con el Derecho una relación estrecha porque ambas buscan, de una u otra forma, establecer principios y valores comunes reconocidos por la sociedad humana como válidos. Bajo esta óptica, es posible asegurar que la competencia inicial entre los dos mundos es aparente y que ella tiende a encaminarse, en un segundo momento, en la misma dirección.

Una vez establecido esto -y es un aspecto que los juristas tienen dificultad en asimilares forzoso reconocer que el Derecho debe alejarse de las tendencias maniqueístas que conducen inexorablemente a los radicalismos. Así, de nada sirve ignorar los datos técnicos y sociales generados por la ciencia con vistas a mantener, a toda costa, la pureza de reglas inadaptadas a la realidad científica ${ }^{14}$; igualmente, se revela sin sentido la imitación del legislador al simple papel de transmisor (o adaptador) de los avances científicos en

\footnotetext{
${ }^{14}$ La evolución fantástica de nuevas tecnologías ha demostrado la inadecuación de ciertos conceptos civilistas, inadaptables a las realidades nacidas del desarrollo de las ciencias. En efecto, una de las mayores consecuencias de los avances biomédicos es el de haber generado la debilidad del ser humano. Surge cada vez un número mayor de cuestiones a las cuales los principios tradicionales del Derecho no consiguen contestar: ¿El embrión humano se encuentra suficientemente protegido sin riesgo de anularse la dignidad humana? ¿Al cuerpo humano es posible reconocer un estatuto diferente de la persona? ¿Qué relación el individuo mantiene con su genoma?
} 
reglas jurídicas continuamente renovadas y adaptadas.

Que el vacío jurídico existe, no queda ninguna duda. Cabe, pues, aceptar el papel decisivo de la ciencia en la construcción del Derecho. O, como lo quiere Mathieu, "a partir del momento en que el papel decisivo de la ciencia en la construcción del Derecho es admitido de manera reflexiva, el Derecho debe intervenir, bajo el riesgo de encontrarse confrontado con el hecho consumado"(14, p.25). En otras palabras, la intervención del Derecho busca aclarar prácticas que permanecieron mucho tiempo alejadas del proceso jurídico y que necesitan, más que nunca, el reconocimiento del orden jurídico, no solo por la garantía que este reconocimiento genera, sino, sobre todo, porque legitimadas por el Derecho reflejan valores dominantes de la sociedad, porque el hombre necesita límites para administrar su propia libertad.

La ley se revela como un instrumento suficientemente flexible para regular las cuestiones relativas a la Bioética. Debe interferir rápidamente, ajustarse a las nuevas conquistas tecnológicas y, siendo objeto de largo debate parlamentario (que puede y debe ser completado por la contribución de estudios externos), viene imbuida de la legitimidad capaz de garantizar la validez de su inserción en el medio social, concretizando el objetivo último de cualquier empresa del sujeto de Derecho: el rescate de la dignidad humana. 


\section{Referencias}

1. Cordeiro RSB. A responsabilidade institucional. En: A moralidade dos atos cientificos. Rio de Janeiro: Ministério da Saúde - FIOCRUZ - Fundação Osvaldo Cruz; 1999: 13.

2. Amaral F. O poder das ciências biomédicas: os direitos humanos como limite. En: A moralidade dos atos científicos. Rio de Janeiro: Ministério da Saúde - FIOCRUZ - Fundação Osvaldo Cruz; 1999: 36.

3. Garrafa V. Clonagem, ciência e Ética. São Paulo: Folha de São Paulo; 1997: 55.

4. Hall MA. Informed consent to rationing decisions. The Milbank Quarterly, 4:645-648.

5. Beauchamp TL, Childress JF. Principles of Biomedical Ethics. New York: Oxford University Press; 2001.

6. De Oliveira Leite E. Exame de DNA, ou, o limite entre o genitor e o pai. En: Grandes Temas da Atualidade. Vol. I. DNA como meio de prova da filiação. Aspectos constitucionais, civis e penais. Rio de Janeiro: Forense; 2000: 77.

7. Villela JB. Desbiologização da paternidade. Revista da Faculdade de Direito da UFMG. Belo Horizonte 1979; 21: 412.

8. Sullerot E. Quels pères? Quels fils? Paris: Editions Fayard; 1992:139.

9. Pegoraro OA. O que é o ser humano? En: A moralidade dos atos científicos. Rio de Janeiro: Ministério da Saúde - FIOCRUZ - Fundação Osvaldo Cruz; 1999: 29.

10. Le Mintier BF. L 'assistance médicale à la procréation. En: Le Mintier BF. Les lois «bioéthiques» à l'épreuve des faits. Réalités et perspectives. Paris: PUF; 1999: 194-201.

11. CECOS (Centre d'Etude et Conservation des Oeufs et Sperme Humains) - L'Insémination artificielle. Paris: Masson; 1991: 5.

12. Neirinck C. Le vide législatif. En: Neirinck C, dir. De la bioéthique au bio-droit. Droit et Société ${ }^{\circ} 8$ Paris: Libraire Générale de droit et jurisprudence; 1995: 119.

13. De Oliveira Leite E. Procriações artificiais e o Direito. São Paulo: RT; 1995: 354.

14. Mathieu B. La necessité de la norme juridique em matière de bioéthique. En: Le Mintier BF. Lês lois bioéthiques à l'épreuve des faits. Réalités et perspectives. Paris: PUF; 1999: 21. 